\title{
Supporting People with Dementia in Digital Social Sharing
}

\author{
Amanda Lazar \\ Northwestern University \\ Evanston, IL \\ lazar@northwestern.edu
}

\author{
Caroline Edasis \\ Mather Lifeways \\ Evanston, IL \\ cedasis@matherlifeways.com
}

\author{
Anne Marie Piper \\ Northwestern University \\ Evanston, IL \\ ampiper@northwestern.edu
}

\begin{abstract}
Sharing online is an important way in which people across the lifespan express themselves, maintain relationships, and connect with others. Yet, people with dementia are often not supported in engaging to the full extent of their abilities, particularly in their interaction with online technology. This paper presents a design case study that examines what it means to design for agency in online sharing involving individuals with dementia. Our work is situated in the context of art therapy for adults with dementia. We present the design and exploration of Moments, a system that allows individuals to share through artwork by manipulating their physical environment. We discuss how designing for agency calls attention to the ways in which the material workspace, including the tools we introduce, and the surrounding social context participate in the creation of agency.
\end{abstract}

\section{Author Keywords}

Sharing; dementia; agency; art therapy.

\section{ACM Classification Keywords}

H.5.m. Information interfaces and presentation (e.g., HCI): Miscellaneous.

\section{INTRODUCTION}

Staying active and engaged online throughout the lifespan has become an integral part of full participation in society. Prior work highlights the importance of designing tools for creating, sharing, and communicating online throughout older adulthood $[13,18,22,31,35,50,67]$. While several systems have been developed for older adults with dementia $[1,32,68]$, these focus on communication alone rather than enabling expression through creating and sharing original content. Older adults throughout the course of dementia already engage in creative self-expression, social sharing, and the creation of original content in offline contexts $[33,48]$. New technologies that integrate with these offline practices stand to enable people with dementia to engage in new forms of self-expression and connecting with others.

Permission to make digital or hard copies of all or part of this work for personal or classroom use is granted without fee provided that copies are not made or distributed for profit or commercial advantage and that copies bear this notice and the full citation on the first page. Copyrights for components of this work owned by others than the author(s) must be honored. Abstracting with credit is permitted. To copy otherwise, or republish, to post on servers or to redistribute to lists, requires prior specific permission and/or a fee. Request permissions from Permissions@acm.org. CHI 2017, May 06 - 11, 2017, Denver, CO, USA

Copyright is held by the owner/author(s). Publication rights licensed to ACM.

ACM 978-1-4503-4655-9/17/05 ...\$15.00

DOI: http://dx.doi.org/10.1145/3025453.3025586
This paper presents a design case study of technology for social sharing - or sharing for the purpose of communicating with social contacts and fulfilling relational goals - involving individuals with dementia. Our work is situated in the context of art therapy. Art making provides a language for self-expression, communicating needs, and connecting with others [33]. Yet, none of the individuals in this study use computers or go online, and because their artwork is created within a protected health care setting and a larger culture of dementia care, they have limited opportunities to engage in sharing through their work. Thus, the people involved in an individual's care (e.g., therapists, family, staff), make many of the decisions regarding sharing with little input from the individual with dementia [17]. We developed Moments (Manipulating Our Material ENvironment To support Sharing) as a way of supporting individuals with dementia in participating more fully in discussions and decision making around social sharing. In turn, we use this system to more deeply understand issues of agency in sharing for people with dementia. Our design process involves: (1) drawing on related work and over two years of field work to create paper prototypes that leverage familiar objects, space, context, and cultural practices related to sharing; (2) paper prototype testing with eight art therapists to understand which metaphors and physical props could support people with dementia in social sharing; (3) development of the Moments system, which integrates a tablet computer in an art frame and recognizes physical objects to allow exploration and specification of sharing intentions; and (4) an initial case study evaluation of Moments with two people with dementia and their therapist.

Our design inquiry examines what it means to design for agency involving people with dementia. The field of HCI has begun to understand design involving people with dementia through concepts such as personhood $[64,65]$, felt experience [41], and the Third Hand (i.e., the empowering facilitation of others) [33]. Taken together, these concepts recognize that agency, or the capacity to act [58], exists throughout the course of dementia, although people with dementia are often not treated as though they have this capacity. People with dementia can be restricted from acting in various domains of their lives due to legal and biomedical frameworks $[9,37]$, which are in place to protect their wellbeing, along with societal misperceptions and stigmas around what people with dementia can and cannot do [28]. People with dementia often have a limited role in decisions concerning their health, finances, wellbeing, and even technology use $[11,25,48]$. 
Our work attends to the ways in which technology design can support individuals with dementia in taking a more active role in one facet of their lives, the process of social sharing, and through this opens up a discussion of what it means to design for agency in the context of dementia. We first provide an overview of the concept of agency and then apply this theoretical framing in the design and exploration of Moments. Finally, we discuss what it means to design for agency in the context of dementia and social sharing.

\section{AGENCY, DESIGN, AND DEMENTIA}

The notion of agency has a long history in the field of HCI, from debates over what it means to feel 'in control' of technology $[19,34,54]$ to questions of where agency is located and whose agencies matter [58]. The dementia literature contains its own debates that bear on the notion of agency: the concept of personhood understands that social interactions have the potential to foster or erode a sense of self [12]; and the concept of citizenship considers the broader sociopolitical context in which individuals with dementia exist and are empowered to act or not (see [6] for a review).

In debates of agency, some have drawn distinctions between playing an instrumental role in carrying out an activity versus having a goal fulfilled, regardless of who performs the work of achieving that goal [21]. This is particularly important in the context of dementia because, in some clinical care contexts, people with dementia are not supported in opportunities to interact with their physical world (e.g., selfcare activities such as washing or feeding [46,55]), which can be taken for granted in other discussions of agency. Individuals with dementia are largely treated as "service users" [45], with staff addressing all of their physical needs, rather than individuals who are able to contribute to interactions in the physical world. Researchers stress the need to support individuals with dementia in manipulating their physical environment in ways that are meaningful in a broader social context, such as crafting a gift for a staff member's baby or folding fliers for a church bazaar [36].

While the ability to meaningfully interact in one's physical world is an important aspect of discussions of agency, we must also attend to the way in which agency is "qualified and constrained by the social, political, and economic opportunities available" ([53] cited in [21]). That is, agency is enacted in a broader context in which certain individuals are permitted or denied the opportunity to participate. In the context of dementia, legal and ethical frameworks limit a person with dementia's ability to participate in many aspects of their life. The notion of legal capacity [37], for example, relies on one's "ability to understand and appreciate the consequences of his or her actions" [2]. Though in some countries, people assessing capacity are required to take measures to "enhance" the ability to understand by ensuring "information is presented in a clear and appropriate fashion," it is not always clear how this should be done in practice [9].

Although decision making ability for people with dementia should be evaluated on a case by case basis, this may not occur in practice. Once someone is labeled as having dementia, clinicians may assess capacity informally and without facilitating an environment conducive to understanding [57]. Individuals designated as a power of attorney (POA), who help make decisions for individuals without legal capacity, may disregard an individual's preferences even when legal capacity exists in a certain context and make decisions based on what they think is best for the individual [26]. To counter much of what happens in practice, recent movements advocate for individuals with dementia as capable of expressing their desires regarding their lives and highlight the importance of the social context in achieving agency in decision making $[6,25]$.

Agency, however, is not simply bound up in the social or material world, nor is it an attribute of humans or materials. Instead, agency is generated through configurations of people and their interactions with each other and their material environment and is situated within particular sociocultural contexts $[5,47,58,60]$. Agency unfolds through interactions between humans and objects through a process of meaning-making: "not only do the humans construct meaning out of their representational acts, but the objects themselves actively contribute in the meaning making process" [60]. Further, agency "is always inextricably tied to the specific sociomaterial arrangements of which we are part" [58]. Thus, new technologies for social sharing are part of these "sociomaterial arrangements" and participate in the process of meaning-making.

\section{Social Sharing as a Context for Design}

Sharing - both online and offline - is a pervasive part of many people's lives. Yet, the simple act of making decisions regarding what, when, and how to engage in social sharing can present insurmountable challenges for individuals with dementia - due to lack of appropriate material resources as well as a supportive broader social and cultural context [17].

Though much technology is designed for people with dementia, very few systems focus on supporting social sharing [61]. When smartphones and tablets are developed for people with dementia, they often focus on functions for cognitive support (e.g., reminders [4,42], cognitive training $[10,68]$ ) or safety (e.g., monitoring or navigation $[4,42,66])$, and place less focus on supporting social communication. Systems that do emphasize social sharing often use existing media to stimulate reminiscence as a way of supporting colocated [1] and remote [32] interaction. There are few systems of this kind and none to our knowledge that focus on sharing content generated by individuals themselves.

Communication technologies for people with dementia are often designed to accommodate cognitive changes by reducing functionality and interface complexity, or "reduc[ing] the volume of information which needs to be remembered" [3]. Another approach is to design in ways that draw on the strengths of individuals with dementia, for example, creating phones with pictures of family and friends that people can recognize rather than needing to recall names 

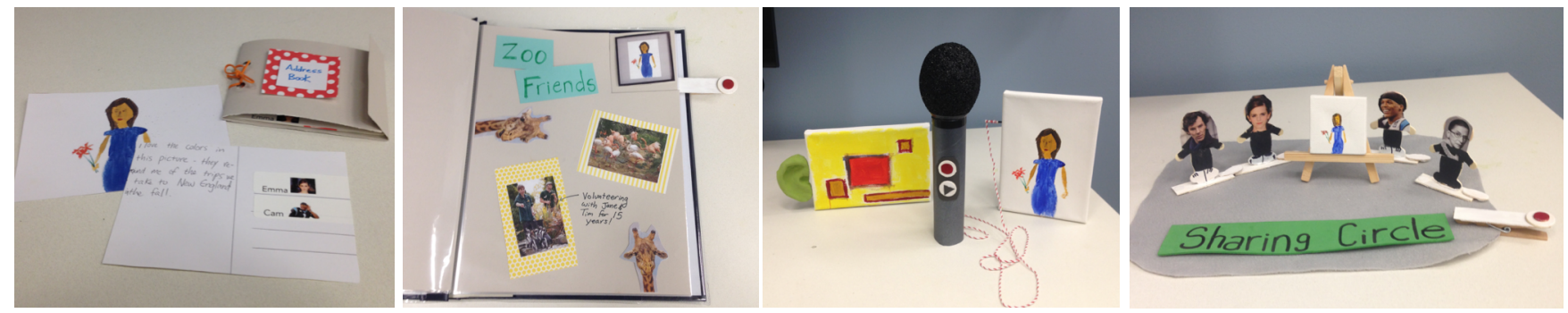

Figure 1. Sharing prototypes include: a postcard and address book; scrapbook; microphone and ear; and sharing circle.

or phone numbers $[4,62]$. However, these tools are often designed for or work best with people in early stages of dementia (e.g. $[42,62])$ as they still rely on significant abstract reasoning and memory, abilities that change throughout the course of dementia.

\section{'Giving Voice' through Embodied Meaning-Making}

Recent work in HCI highlights people with dementia's ability to express themselves through embodied interaction with their material environment and other people [24,29,41]. Wallace et al. studied the ways that objects (e.g., digital jewelry, interactive art installations) can support people with dementia in expressing and maintaining a sense of self $[64,65]$. People with dementia regularly express themselves through embodied interaction with other people and their material environment. Researchers have begun to attend to how these expressions and offering new material resources for engagement (e.g., props) can open up avenues for design $[33,41]$. This prior work takes advantage of the arts (e.g., music [40], visual arts, $[33,64]$ ), which offers a supportive context for people to communicate through multiple modalities and without strict conversational rules $[17,33]$. Thus, the present paper draws on the arts, and art therapy in particular, as a way of situating the design and exploration of agency in social sharing.

\section{EXPLORING PHYSICAL SHARING PROTOTYPES}

With a view of agency as created in interaction through particular configurations of the social and material world, we turned our attention to the social context of sharing as well as how material representations of sharing 'talk back' $[51,60]$ and can participate in the meaning-making process.

\section{Method}

This project emerged from over two years of field work involving an art therapy program for adults with dementia in an assisted living and memory care facility. Prior analyses detail the facilitating role of the therapist in creating artwork [33] and the importance of sharing through artwork [17] but leave open many questions around how design could enable people to more fully participate in social sharing. We created four paper prototypes (see Figure 1) based on weekly observations of art therapy over the course of two years (group and individual sessions in which we took photographs, audio recordings, and debriefed with the practicing therapists), and interviews with eight family members and friends. We also drew on prior work in art therapy and related studies involving people with dementia, which emphasize the importance of physical props [41], recognition over recall [52] and contextual cues [7] in meaning-making. Each prototype was designed with those features in mind and to highlight various dimensions of physical objects, space, and how concepts such as specific message recipients, groups of people, and public audiences could be conveyed. The prototypes include: (1) a postcard and address book with names of individuals on stickers that can be added to a message on a postcard version of artwork, (2) a scrapbook in which artwork can be positioned beside pages containing contextual information about people in one's life, (3) a microphone and ear that connect to artwork to explore audiences (e.g., announcing or whispering messages), and (4) a sharing circle that uses physical space, proximity, and the placement of objects representing people and artwork to configure sharing preferences (i.e., an individual moving a figure into the sharing circle means they would like to share a piece of artwork with them).

We introduced the paper prototypes during in-depth interviews with eight art therapists (all female, 1-16 years of experience) in an open and flexible way to understand how therapists would interpret these materials in interaction. All therapists currently or previously worked with adults with dementia. In this paper, we use the term residents to describe the individuals with dementia with whom these therapists work in care settings. We took photos of interaction and audio recorded and transcribed the interviews for analysis. We also drew on data from our field work in art therapy involving residents and their family members. Our approach to data analysis involved iteratively coding data through a process of open coding, axial coding, and memoing [14,15]. We discussed emerging themes amongst our research group and with a collaborating art therapist.

\section{Findings}

Sharing through Artwork is Positive but Limited

As reported in prior studies [17,33], sharing artwork within art therapy sessions, directly with family members, or to a broader public in art exhibitions allows residents to connect with others. AT2 said of residents she works with, "...they tend to feel very isolated... they have stories to tell, and they want to tell them." AT4 explained that sharing art online could provide an "opportunity to connect people who are historically isolated to others in their life." People with dementia retain their ability to be creative and tap into long 
term memories to tell stories [55], and artwork becomes a vehicle for sharing those expressions. AT4 also noted that families may not know "how to... have a relationship with the person with dementia." Artwork can serve as a mediator for family communication and relationship building and instead of "quizzing" a family member with dementia with " What's my name? How do you know me?'... It gives them [family] something external to focus on together that's strength based," said AT8.

Artwork can also serve as a physical artifact that can be shared with and gifted to family members. AT5 said, "There are definitely specific times that people would be like 'I need my daughter to see this... or they make something specifically for a person." Similarly, one resident said, "I have something sometimes I'd like to talk to [specific people] about. Not necessarily artwork." Residents may have a desire to share an artifact directly with a specific individual or to share a collection of work at the end of life. Interestingly, several therapists mentioned residents' desires to share or give artwork to a deceased relative or friend, as residents may feel a need to connect with an individual that they may or may not realize has passed away. AT5 explained that "having other people see the work she made for her [deceased] sister...that felt like it was at least one half of that giving and receiving relationship was met." Sharing or gifting artwork, regardless of whether the recipient is still alive, can fulfill a resident's need for connecting with others.

Residents, however, are heavily reliant on art therapists to facilitate sharing in a variety of ways; therapists may have to remind an individual of the options in sharing (e.g., names of and relationships to loved ones) and perform the work of sharing (e.g., emailing family members, assembling an art show). Several therapists noted their desire to email residents' art to family or friends, but this posed a variety of challenges, including the time required and restrictions based on the context of care. Therapists wanted a seamless way to share artwork that fits into their current practices.

Legal and Ethical Considerations around Sharing

Legal and ethical frameworks also limit an individual's ability to make decisions around sharing and carry out associated actions. Sharing therapeutic artwork is further complicated by it being made in a clinical context. AT4 noted that though the person with dementia should own the artwork, "it becomes part of a medical record. And therefore, it's protected by HIPAA." Based on the Health Insurance Portability and Accountability Act (HIPAA, legislation passed in the United States), many art therapists treat artwork and its links to patient information (e.g., names, diagnoses) as protected health information [30]. While information can be disclosed on a "need to know basis," as AT3 said, therapists seek consent before sharing artwork more publicly (e.g., in art shows) [17], noting a process of verbal consent from the resident, written consent from their power of attorney (POA), and even notifying additional family members. Yet, families differ in their desires to have residents' work shared, and ultimately the POA decides whether a resident's artwork can be shared. Several therapists described families who were enthusiastic about sharing artwork, and family members at our field site were eager to receive artwork via email and even offered to help a resident post their work on Facebook. In contrast, AT4 mentioned knowing of families "shamed by cognitive impairment, " which could affect their willingness to agree to sharing artwork. Though legal and ethical considerations are intended to protect people with dementia from abuse and exploitation, they also end up limiting their role in decision making process around sharing their work.

Of central concern, sharing, even in person, can introduce new vulnerabilities. Working to protect a resident's image, therapists sometimes act in ways that effectively restrict a resident's ability to share certain information. AT2 mentioned "wanting to make sure that I can protect her [resident's] interest... she really wants to share, but then she goes off on these crazy...inappropriate tangents." Therapists feel a responsibility to consider how residents may be perceived when displaying their artwork, particularly in more public art exhibitions. AT4 described this as a "responsibility on the art therapist's shoulders." Art therapists balance the artist's desire to share with legal and ethical considerations that arise in a clinical context:

"We live in such a litigious society and these organizations are very nervous about the family coming back, and being like 'How did you let my mom share this story, '...adding dementia to this realm...adds a whole other layer of protection..." (AT4)

Digital sharing tools further complicate these issues [27,49]. Therapists cautioned about friends seeing the artwork online, noticing changes in someone's artistic style, and associating that with dementia. Others described the risk of opening residents up to criticism online. AT8 said, "What if it got turned into a meme and then people are laughing about this person...", also noting that she wanted to document residents' decisions in the event of "the family possibly taking legal action or something... "Some therapists felt that despite the legal and ethical layers that prevent people with dementia from sharing, sharing is appropriate "as long as it's the client speaking for themselves," said AT3. Similarly, AT8 feels that "it's their [resident's] choice and that they are wanting to share it with the public because they have something to say or they want people to know who they are." For example, one resident had been a professional musician, and sharing publicly was part of her identity. The resident explained, "When I play the piano I love to perform and you spend hundreds of hours learning a program but then you can share it with people." This resident likened sharing audio recordings about her artwork in a recent art show to a performance, and said, "It's got a performing aspect to it and that's what I really liked." Thus, therapists negotiate an individual's will to share their artwork against a backdrop of legal and ethical tensions around sharing. 
Involving People with Dementia in Sharing Decisions Therapists regularly seek ways to involve people with dementia in making decisions around sharing artwork, but this takes place primarily through in person discussions that are not preserved, are largely verbal, and rely on abstract tools such as consent forms. When shown the sharing prototypes (Figure 1), therapists responded enthusiastically to the idea of engaging people in discussion in a more embodied and contextualized way. Hence, much of the discussion involving the paper prototypes centered around the tools and metaphors that would best convey the experience of digital sharing to residents, which we present below as design considerations.

(1) Draw on familiar artifacts and cultural practices around sharing to make resulting actions visible. Therapists explained the importance of building off well-understood metaphors for sharing and existing sharing practices. Specifically, they thought that the postcard and scrapbook prototypes conveyed the idea of sharing most clearly. AT1 said, "You know that anything you put on the postcard, that's understood that that's going to another person... If we're talking about sharing online, it's the most clear metaphor of 'this is going to somewhere'." Regarding the scrapbook, AT5 noted that it "is something that older adults grew up sharing. So you know you take your photos, and you fill them in the album and then you sit down." In other words, the familiar social practice of sending a postcard or sharing a scrapbook is likely to convey the type of sharing to take place. While the postcard had an address book with images and names, the scrapbook included people in the resident's life on each page (e.g., daughter, specific group of friends). AT8 thought that having this collection of people in their life would serve as a conversation piece, although others thought the images would be so emotionally evocative that they would distract from seeing the images as options for sharing.

(2) Use physical movement and space to express intentions and choice. Therapists thought the idea of physically manipulating objects within this space would give residents " a sense of control and choice" (AT2) and enable residents to play an active role in dynamically specifying their intentions. AT8 noted, that the sharing circle locates the ability to make decisions "in your own body, so that you're actively showing what your choice is... it seems like it would be a little bit more of a concrete way to know that they're understanding." Therapists saw value in how the sharing circle exploits physical placement and proximity of objects as a way to indicate intentions for sharing. AT7 said "I think it's nice that it's physical, [that] they physically have to put somebody in the circle, because that makes a lot of sense." AT5 said, "this [sharing circle] invites the bilateral, greater movement of the body to be interacting," which is important in encouraging residents to participate and focus on their actions. AT6 said, "I think there is more ownership given to the person... The artist can be invested in not only what they made but what they're gonna say about it and who gets to hear that." Therapists also saw the sharing circle as a way of helping residents roleplay scenarios and envision audience reactions. Relatedly, therapists noted the playful nature of the sharing circle. AT7 said, "it feels like a game... which I think is a good thing in many ways because [it is] inviting them to engage kind of playfully."

(3) Immediacy, repetition, and context are important in discussions of sharing. Therapists explained that discussing sharing within the moment of art making is one way of helping residents play an active role in this process. AT7 said, "anything that's done later is not involving them and becomes more removed from their autonomy." Yet, AT2 described a resident with significant, progressive cognitive impairment who "would say things to me, and immediately contradict what she just said and make decisions, and then decide that wasn't what she wanted." This therapist (and others) took the presence of cognitive impairment into account in decision making by repeatedly going through consent forms and ensuring that the resident continued to maintain the same position. AT7 said, "When I'm discussing sharing with a client...the conversation happens multiple times, it can't just happen once." Some therapists expressed the need to have a residents' intentions and message be consistent over time before sharing it, and they envisioned using a digital system to help achieve this. Further, providing context each time sharing takes place is important, as AT7 said, "I make sure that I use language that reintroduces the whole context... trying not to take for granted that they know what context I'm talking about." Therapists also reminded residents of the audience for their work in ways that point out possible negative implications of sending it to those individuals, while being mindful of seeming condescending.

(4) Audio is important for capturing expressions but requires revisiting and editing. Therapists noted the importance of incorporating audio recording in a sharing system in addition to written and visual information, in part because speech works better for some individuals. However, therapists wanted residents to be able to listen to and edit audio before sharing, both in the moment and over multiple days or weeks. Beyond editing audio recordings for content that should not be shared, therapists wanted the flexibility to allow audio messages to evolve over time. An audio recording preserves feelings at a particular moment or story. AT3 explained that residents' messages often change over time and that they should not be "stuck with this one particular dialogue that was recorded under one circumstance." AT2 also cautioned that although revisiting a previous recording could help some reconnect with their art, it also imposes a particular story which may lose relevance or salience to a resident.

(5) Use physical props to represent audience in a concrete and visible way. Therapists gravitated towards more concrete representations of audience, such as names and images in the address book and figurines within the sharing circle. Additionally, therapists thought that the microphone prototype made the idea of speaking to a larger audience clear. AT1 explained that "It's a nice physical reminder of 
what's going on... You're not gonna forget that you are speaking to a wider audience." AT7 described the microphone as "very visible, it's big and bold." AT3 also mentioned that the microphone could be used to "build strength to their voice before talking to somebody" and that "it could just really provide a lot of encouragement... and build self-esteem." Therapists wanted to incorporate the microphone into practice immediately.

\section{SYSTEM DESIGN AND EXPLORATION}

Building on our formative work, we designed and developed Moments as a way of understanding how a therapist and resident, working in coordination with each other [33], draw on new types of physical and digital resources as part of discussions of sharing. In turn, we analyze how the system itself, when used in this context, participates in the process of creating agency in digital social sharing.

\section{Method}

Based on the interviews described in the previous section, as well as over two years of observing residents in art therapy (including the residents who took part in the case studies described below), we introduced versions of the paper prototypes into an art therapy program within an assisted living and memory care facility. The majority of the adults we interacted with in art therapy live in the skilled nursing portion of this community and have dementia (i.e., from Alzheimer's disease, vascular dementia from stroke) that affects memory, speech and language, and physical abilities. Working primarily with the lead therapist at our field site, we sought feedback on the system design and potential physical props. This therapist used refined versions of the paper prototypes in her practice and explored the concepts during individual and group therapy sessions. One researcher observed the sessions and took notes. After each session, the therapist debriefed with the observing researcher. Our methodology relied on close collaboration with the therapist through a process of generating and refining ideas. We encouraged the therapist to appropriate the sharing prototypes as she saw fit and rapidly adapted the tools to better fit the particular individual and their specific goals. For example, we brought in paper labels with residents' family members listed on them, customized photographs with labels, images of each resident's artwork, and a working microphone/speaker.

We then used these insights to refine the design of Moments, described below, and configured it for two individuals who participate in art therapy. The therapist identified these two individuals because of their desire to connect with their family members and friends but limited ability to do so in their current environment. These two participants used the system individually with the therapist while a researcher observed and took notes. Rather than interviewing the older adults directly, we had the therapist ask questions about their perceptions during the testing session. This allowed us to draw on the therapist's long standing and close relationship with her clients to overcome communication difficulties we

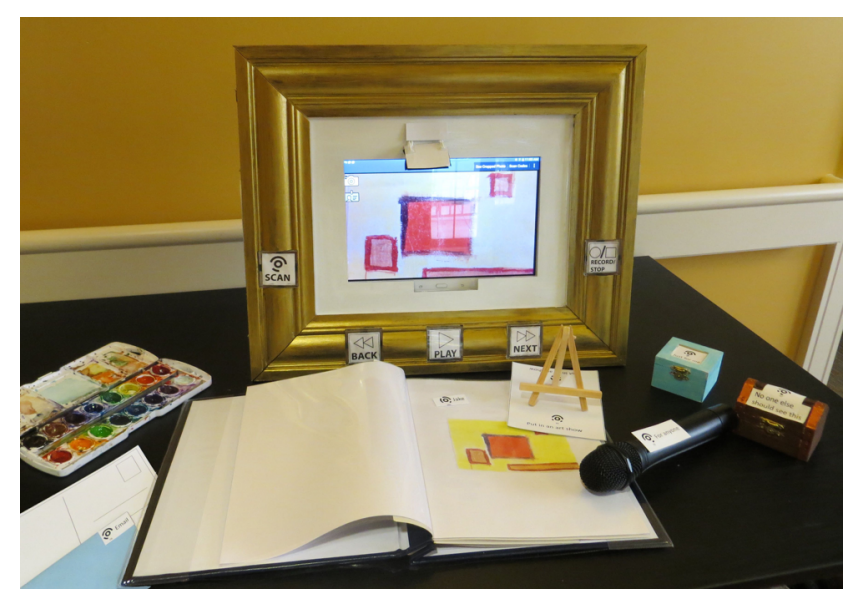

Figure 2. Moments incorporates an interactive art frame with physical buttons that supports creating and navigating an art portfolio. The system detects tagged physical objects and associates their meaning with pages in the portfolio. The therapist selected a subset to bring into each session.

might have as outside researchers. We also interviewed residents' family members and friends to gain a more complete picture of the dynamics of social sharing.

\section{Hardware and Software Prototype}

Prior work notes that framing artwork in this context calls attention to artifacts and positions them as worthy of sharing with others [33]. Drawing on the idea of a frame as another useful metaphor for sharing, we created the basis of our prototype by mounting a Samsung Galaxy Tab Pro 12.2" tablet inside a wooden art frame. As prior work also suggests the importance of having clearly labeled, tactile buttons [33], we added physical buttons around the edge of the frame using an Arduino IOIO board and five Breakout PCB boards with button pads. The buttons connect to the graphical display and can be reprogrammed and relabeled for flexible reuse. We used a mirror to redirect the tablet's front-facing camera to capture the space on the table in front of the frame.

We created an Android application that maintains individual portfolios of work (i.e., collections of images or other media) for each resident. Working together, the art therapist and resident can capture images of artwork and use the interactive physical buttons to record and replay audio to accompany the image. The physical tabletop space in front of the art frame is also interactive, allowing the therapist and resident to bring in physical objects that are recognized by the system. We used the TopCodes tagging library [69] to enable users to dynamically add printed tags to physical objects and paper materials. Our application supports four tag types, which work in combination with each other, and include: (1) specific audience, which designates a particular recipient (e.g., Jane, my daughters); (2) general audience, which specifies who may view this information (e.g., public, all family, staff, only me); (3) sharing actions, which specify online or physical acts of sharing (e.g., send as email, add to an art exhibit), and (4) a crop-save action, which captures content within a particular region bounded by tags (e.g., 
writing, word tiles). Pressing a physical button on the frame captures and interprets the tags for that particular resident, saving the information to that page in their portfolio.

Based on our findings with the paper prototypes, we created a range of paper and physical materials that work in conjunction with the interactive frame (see Figure 2). For example, a resident can create a paper postcard of their artwork and bring in physical word tiles and images of family members to indicate recipients, which could be automatically emailed to recipients. Paper scrapbooks can be augmented with tags so that each page becomes interactive when placed by the digital frame, linking content on each page with specific individuals and messages the resident wants to convey. Bringing in a letter envelope may send the information on that page via email. Residents can also arrange objects that denote general audience permissions, such as a locket with the words "just for myself", and link that information to specific content in their portfolio. The application allows customizing how physical objects and their tags are interpreted by the system for each individual.

Currently, the system displays the desired sharing intentions on each portfolio page for the therapist to review with residents; however, the system does not yet perform online actions (e.g., sending a message via email). This limitation is in part imposed by our collaborating field site, with whom we are working to explore issues of online sharing before these actions take place online. The therapist, however, intends to carry out the wishes of the resident as part of her ongoing art therapy program (e.g., send artwork and audio in an email). Although the system is not yet fully functioning online, we provide two case studies of use that explore how residents and their therapist cooperatively use this interactive physical-digital space to create agency in sharing.

\section{Case Study: Emotional Connections through Sharing}

Joy can read and understand spoken language well, and mostly communicates through gestures and nodding her head as she is unable to form coherent sentences due to a stroke several years ago. Her stroke also resulted in vascular dementia, which affects her short-term memory. Joy's family values her artwork immensely. Her daughter explained that when she visits Joy, she takes pictures of Joy's artwork and sends it to her siblings. That daughter also facilitates the distribution of Joy's physical artwork, sometimes involving Joy by asking if she agrees that a particular piece of art should go to a particular family member. At the time of the development of Moments, the family member was preparing to go to a family trip where she would distribute several pieces of Joy's artwork. The daughter explained that she already selected art pieces for herself and her sister, but also intended to give some artwork to Joy's grandchildren. The therapist decided to do a session with Joy to "give the resident more agency-or more of a role in that discussion." In this case, the resident's family was actively involved in negotiating ownership of her artwork and the art became like a prized possession to be gifted to certain family members.

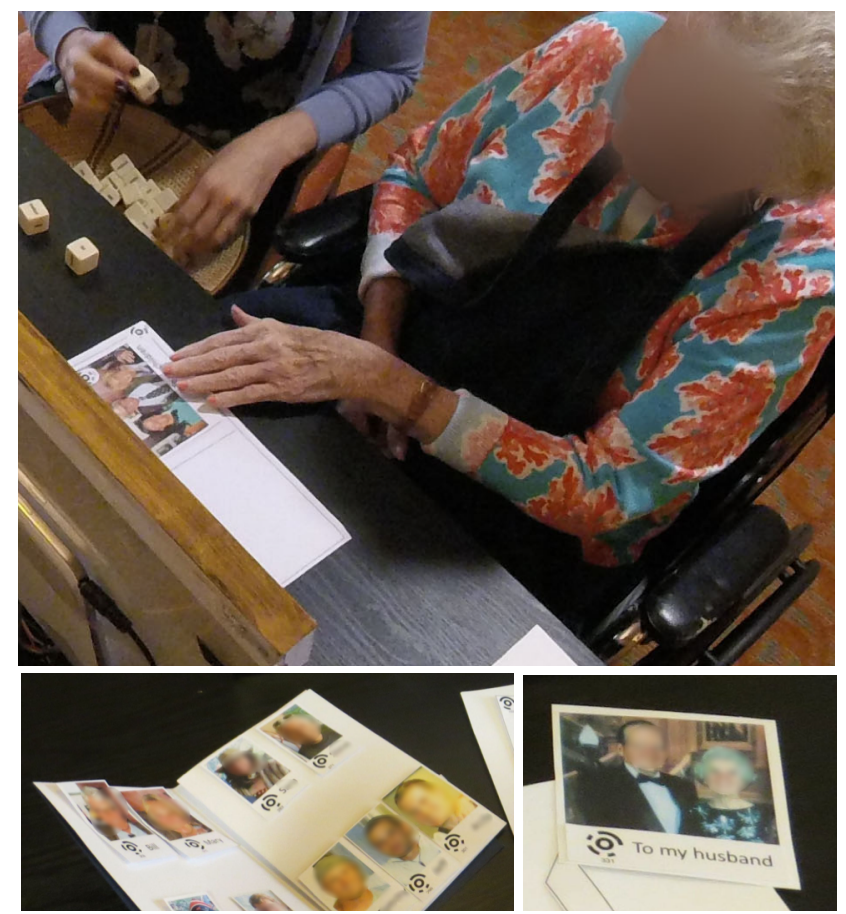

Figure 3. Joy used a photo address book (bottom) to identify message recipients. She positions the photo labeled "to my children" in the postcard address location and adds word tiles in the message area (top).

To give Joy more of a voice in the gifting process, the therapist printed labels with the names of the three grandsons. She then showed Joy's art pieces to her and asked her which of the pieces she wanted to give to each of her three grandkids. Joy also selected word tiles to accompany each of the three pieces of art, which appeared to describe the individual recipients more than the art itself ("eyes happy" and "love glorious"). As she looked at the words she chose for her grandsons next to their names on her artwork, she reached out to pat them and began to cry, seemingly happily. The therapist said the experience of gifting artwork appeared to be extremely meaningful to Joy. Joy's artwork and the other media she chose to accompany it (i.e., word tiles) enable her to initiate and participate in a family dialogue despite her not being able to speak [33]. Furthermore, gifting enabled her to participate in a reciprocal relationship with her family $[20,56]$, which people with dementia are not always supported in doing in other areas of their life. However, this relied on Joy giving away the actual art piece itself, which may be inappropriate for pieces that are sentimental or part of a therapy portfolio, and involves the logistics of getting an art piece to another location.

To explore ways that art could be transferred digitally, rather than sending the artifact itself, the therapist chose to have Joy use a paper postcard with Moments. The printed rectangular postcard includes codes that initiate a cropping and saving action so that the content on the postcard is stored in the system. We also created a paper address book with names and pictures of Joy's family members as well general 
audience permissions (including "to anyone," "just for me," "to my children"; see Figure 3). The therapist explained that these materials would work well for Joy "because she can't tell me who [she wants to share with], but she could pick a sticker." Thus, creating agency in this moment involves having representations that enable Joy to express (and the therapist to interpret) her desires regarding sharing.

After making art together, the therapist and Joy used Moments to capture, annotate, and share her work. Joy responded to the materials in front of her by placing the image of her family members in the address area of the paper postcard and the word tiles in the message body. The therapist explained that "she can clearly understand if you put a picture there it means it's the address." While using Moments with Joy, the therapist chose to explore the general audience permission labels to narrow down the people that Joy wished to share with, then turning back to pages with images and names of specific individuals that fall within those general audience categories. The therapist explained, "That was really helpful that she said I want to show this to my children... I could turn back and say are you talking about specific children or just your children in general." The therapist readily adapted the materials and brought in new representations as part of their process of meaning-making.

In our formative work, therapists mentioned a concern that residents would find images of family so emotionally evocative that they would have difficulty interpreting the resident's interest in the photo itself versus a desire to share with those in the photo. The therapist explained that Joy seemed to have a strong response to the photos of her family but that this emotional salience also led her to connect with her work in a way that she had not in previous therapy sessions. Joy appeared very excited to see the images of her family and once she had chosen words as she had in the previous session, she repositioned and patted the image and words. At one point, she began crying. The therapist said:

"This is the second time that she's gotten emotional...in response to being offered the opportunity to share with specific people, and both times it was a happy emotional... When she was doing the artwork for her grandsons, it was the fact that she was sending them a message was when she started crying, and I felt like that was the same timing today, it's when she wrote 'my love precious' and then that was associated with the picture, that she was going back and forth from petting the picture and petting the words."

Joy's interaction with the material environment - her selection of artwork, emotional response to viewing loved ones in photos, arrangement of word tiles, and tenderness in arranging these in space - provided a new form of expression for Joy but also offered the therapist insights into Joy's connection and desires in this particular moment. Thus, the material environment itself is an integral part in the process of creating agency. Observing this, the therapist used Moments to save this configuration in Joy's portfolio but also attached these artifacts to the actual artwork, as she "wanted her [Joy] to retain a trace of that too...so that the physical artwork also carries the history of how it's been shared." These traces of sharing and the decisions that took place also represent the unfolding process of agency.

\section{Case Study: Sharing to Connect with the Past}

Sue tells many stories that connect to various parts of her life, including memories of her past and her values in the present. Sue has moderate dementia, and her family is very important to her, and though at times she is unable to generate the names of her children, she tells many stories about them. Unlike Joy, Sue's family does not actively distribute her artwork, so the therapist helped assemble a scrapbook of Sue's artwork, as she was likely to keep much of her work to herself. Additionally, Sue connects to her work and generates stories about her artwork each time she views it. A scrapbook lends itself to being revisited with new stories being layered on each viewing.

In a previous session, Sue had drawn an image labeled "Those I love" where she drew images and wrote names of different people in her family. These images and names were used to create labels that Sue could use with her scrapbook. Sue chose the labels and images associated with her daughters. The therapist prompted Sue to record a story about a piece of artwork for an individual she selected. She hesitated, and the therapist handed her the microphone, after which Sue naturally began speaking in response, and recorded the message "I love you and I miss you." The microphone, and the interaction of being handed a microphone, played an active role in enabling this interaction to take place. Sue responded to the concept of associating individuals and messages with her artwork, as she recorded other messages that signaled audiences (e.g., "you all") and would end in a way that signaled the closing of a message. For example, one message she recorded was " $\mathrm{Hi}$. I love you all. Mom." Though at times she did not appear to recognize that she had made the artwork in the scrapbook, she was able to tell stories about her artwork that she then connected to the individuals she associated with that piece.

Although the therapist could potentially share just Sue's artwork with those identified by Sue's labels, the way that Sue carefully laid out the labels, accompanied by her writing and audio recordings, are important components that could be meaningful to family members. Further, this positioning and layering of physical and digital materials represents Sue's role in the process of configuring her desires around sharing and this organization is part of the message itself [39]. Currently, these representations are not saved over time and the digital media (i.e., audio recordings) are disconnected from the content and her wishes for sharing.

The therapist expressed a need for a better way to capture and revisit this interactive content and used Moments to extend Sue's scrapbook that they began together. In one session, after making art side-by-side, they captured an image of Sue's artwork with the system and then inserted Sue's artwork into the physical scrapbook. Though Sue does 


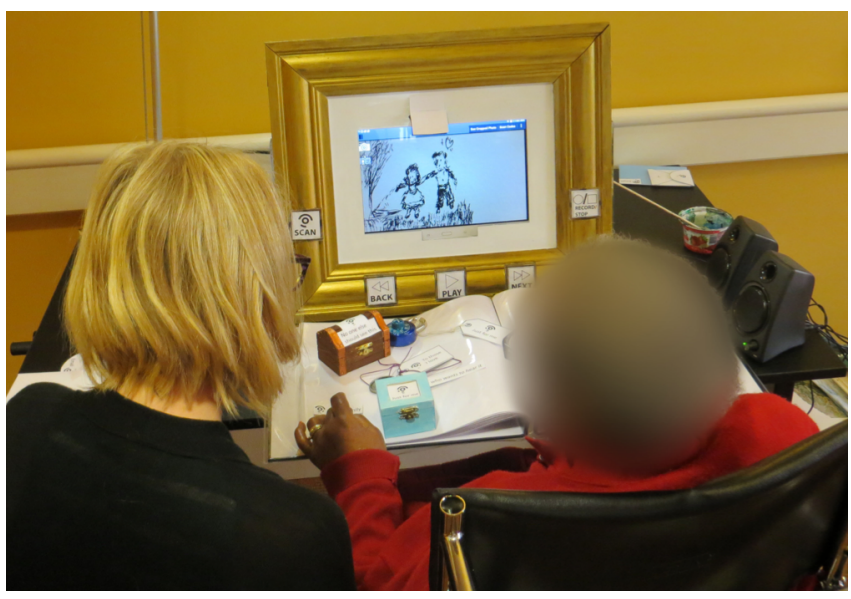

Figure 4. Sue uses Moments in conjunction with her existing scrapbook and objects representing audience permissions.

not use computers, she pressed buttons on the frame with little or no prompting. While Sue needed the cuing of being handed a microphone previously, she easily operated the record button on the frame. In the past, the therapist needed to interpret Sue's body cues and intonation to know when she was finished recording a comment. In this sense, the physical buttons were successful in enabling Sue to initiate and end her message. At a functional level, certain elements of the interface design can enable residents to play an active role in the sharing process. Further, some scholars have argued that this low-level, proprioceptive control over one's environment is part of the creation of agency [19], insomuch as the design and social context avails these interactions.

After Sue recorded her audio, the therapist asked her if she would like to share her audio or if she wanted it to be just for herself. Sue responded, "so far, it's just for me." Then, the therapist put several of the physical prompts in front of her, including several objects that said "just for me" (e.g., locket, treasure chest), and Sue selected "to my family," shifting the audience she wanted to share with. Here, the therapist's laying out of these objects calls attention to certain possibilities and allows Sue to shift the course of sharing. As noted in our formative interviews, the therapist addressed this resident's decision change by repeating the decision in several different ways and hearing the client reaffirm this decision to verify that she wished to do so. Additionally, the therapist played back her audio using the physical button on the frame and later explained, "I felt it was helpful to repeatedly play the audio because I do know that she forgets throughout a session what's been said before or what happens before." The ability to revisit audio recordings alongside the artwork and representations of an audience, which Sue could touch, hold, and reposition, reassured the therapist of the meaning-making unfolding in that moment.

The therapist explained that using the system "emphasized the step of 'making special'." The concept of 'making special' describes the arts as "ordinary behavior made special (or extraordinary)" [23]. In other words, the importance assigned to the arrangement of ordinary materials in the visual arts is what makes the artifact 'special'. Magnifying and featuring the work in an elaborate frame while also linking it with handwritten text, drawn images, and audio helps to both create and preserve the act of 'making special'. Further, this organization helps anchor conversation and provides a persistent reminder of what is being discussed. The therapist noted that Sue's attention was focused on the art in the frame, rather than the physical artwork that was on the table, and that she was able to maintain a connection to the artwork that she had made throughout the session.

After the session, the therapist discussed how "my family" may take on different meanings - "the family [Sue] was referring to was the family that would have been in the time period of this scene. Which makes sense with dementia... she goes right back to that memory." The therapist continued, "She was talking about her mom and her brothers, not her kids... The people she wanted to share this with are...no longer alive." People with dementia experience time differently than those without dementia $[8,38,59]$, possibly resulting in Sue wishing to share with individuals who are not alive. The therapist described wanting to provide the options "to my living family" and "to my childhood family," in order to avoid implying that these family members were alive while "enabl[ing Sue] to feel like she shared that with her brothers." The therapist emphasized the need to support Sue in achieving her goal of connecting with family. That is, for Sue, the creation of agency in sharing centers on fulfilling her need to connect, even with individuals who are not living.

\section{DISCUSSION}

This paper describes the design and exploration of tools for digital social sharing involving people with dementia. Through this, we offer a deeper understanding of what it means to design for agency involving people with dementia while informing the design of future sharing systems.

\section{The Participation of the Material Workspace}

Recent work in HCI highlights the importance of attending to embodied expressions of people with dementia, particularly with respect to interaction with the material environment $[41,65]$. Our work extends this by offering insights into how the material workspace participates in the meaning-making process and creation of agency. When the therapist provided a range of options regarding sharing, individuals responded by interacting with their workspace in a way the therapist could interpret. The physicality of objects helped anchor conversation, and the layering and reorganization of objects provided persistent information about the meaning-making unfolding in the moment. While individual customization of the material workspace is essential, certain physical objects clearly signaled the concept of sharing, such as postcards, scrapbooks, framed artwork, and microphones. Future research can explore how other materials, such as tools for creating music or poetry, and our practices using them, support new forms of interaction for people with dementia. 
As designers, we must attend to how the material workspace 'configures participation' [63] and drives what can take place by making some options available while excluding others. For example, the therapist in our field work explained how sending a postcard "becomes a Herculean effort" and the steps of writing a message, obtaining a stamp, and placing the card in a postal mailbox are often performed by others. While digital systems can address these logistical challenges, therapists cautioned that it is critical that residents "have control over" this process; thus, designers should seek ways of preserving aspects of the process that individuals find meaningful, particularly if they are not currently given opportunities to perform these actions (e.g., selecting and placing a stamp on a postcard). Further, therapists noted that showing residents the outcome of their actions (e.g., that a message was sent) is a part of creating agency.

\section{Negotiating Agency in the Context of Vulnerability}

The therapists in our study were sensitive to the social (and legal and ethical) context in which sharing occurs as well as their role in this process. Therapists already reflect on their actions and potential consequences when they share a photo of artwork with a family member via email or replay audio from a resident in an art exhibition. While art therapy is considered a protected health context, tensions arise due to a view of artwork as self-expression and the complex nature of consent and legal capacity. Our analysis contributes to ongoing discussions of the non-static nature of patient consent and privacy concerns over the lifespan [43].

Therapists are cognizant of how an individual is perceived when sharing information in offline spaces and noted that they would maintain awareness in online spaces as well. The therapist at our field site brought up questions concerning repetitive sharing, noting that individuals with dementia may want to repeatedly share content with a family member. She likened this to repetitive phone calling behavior and explained that family members will sometimes remove the phone of an individual with cognitive impairment in response to this behavior. The therapist said that she must weigh the individual's need to connect with their family, and whether this can be met through other outlets [16], against how a family will perceive repetitive sharing, in part because the family plays a role in negotiating agency (e.g., by taking away a phone). Further, a resident's family and friends can be vulnerable in these interactions too, with digital social sharing providing more information on the condition of their loved one or more visibility into their life, which may be painful for some family or friends. Thus, the creation of agency and how a therapist 'follows through' with a resident's desires is situated in a broader social context and negotiated with others who may be affected by sharing.

The Moments system relies on the therapeutic alliance between the resident and therapist and their established relationship, which is built over time within a particular setting. Thus, designing for agency in this context attends to the interpretive work that the therapist, with specialized training and ethical attunement, brings to interaction. For systems not involving a therapist, staff and family members who have a relationship with an individual with dementia could support interaction. Simply viewing the digital portfolio (or even a printed version) could support co-located social sharing. Future work, however, should consider the different values that each participant brings, particularly when various goals clash (e.g., resident wishes to share a story that embarrasses a family member).

\section{Gifting as a Valued Form of Social Sharing}

Sharing takes on different meanings and fulfills different goals depending on what is shared and how it is shared. Combining artwork with other media (e.g., audio, family photos, objects) adds richness to these expressions. In some situations, the artwork helps evoke stories that family members value, and the artifact itself is less important. Sharing through a digital version of artwork may work well in this case. In other situations, the artwork becomes a prized possession, and the act of gifting artwork can be a way of showing caring towards another person [20,56]. Gifting artwork can help fulfill a need to connect with another person, and this need can be met even if the recipient is no longer living. In the case of gifting, transferring the physical artifact with its visible texture, markings, and even traces of the artist (e.g., fingerprints) is important. Sharing a digital version may miss the intention behind this exchange. Further, gifting artwork repositions the resident as someone who has created something that is valued and worthy of sharing, further contributing to the creation of agency and sense of self $[64,65]$. Beyond artwork, future work should explore how to enable residents to initiate and have a voice in gifting in other aspects of their life, such as treasured family possessions or even digital heirlooms [44].

\section{CONCLUSION}

This paper analyzes how new technologies can create opportunities for individuals with dementia to participate in digital social sharing, an important and pervasive aspect of contemporary daily life. Although the present work advances this goal, there is much left to understand about how online interaction unfolds, supporting reciprocal communication, and long-term use of new sharing systems. Nonetheless, theories of agency help reconceptualize the design of digital sharing technologies as resources for situated interactions through which individuals negotiate these activities. A view of agency as created in interaction through configurations of the social and material world shifts our design focus towards the broader context in which technologies are situated as well as how material representations 'talk back' and participate in the active process of meaning-making.

\section{Acknowledgements}

This work was supported in part by NSF grant IIS-1551574. We thank Raymundo Cornejo and Karina Sirota and the individuals who participated in this study.

\section{REFERENCES}

1. Norman Alm, Richard Dye, Gary Gowans, Jim 
Campbell, Arlene Astell, and Maggie Ellis. 2003. Designing an interface usable by people with dementia. Proceedings of the 2003 conference on Universal usability (CUU '03), ACM Press, 156157. http://doi.org/10.1145/957205.957237

2. Alzheimer's Association. Legal Documents. Retrieved January 1, 2016 from https://www.alz.org/care/alzheimers-dementialegal-documents.asp

3. Claire Ancient, Alice Good, Clare Wilson, and Tineke Fitch. 2013. Can ubiquitous devices utilising reminiscence therapy be used to promote well-being in dementia patients? an exploratory study. Lecture Notes in Computer Science (including subseries Lecture Notes in Artificial Intelligence and Lecture Notes in Bioinformatics), 426-435. http://doi.org/10.1007/978-3-642-39194-1-50

4. N. Armstrong, C.D. Nugent, G. Moore, and D.D Finlay. 2010. Developing smartphone applications for people with Alzheimer's disease. Proceedings of the 10th IEEE International Conference on Information Technology and Applications in Biomedicine: $1-5$. http://doi.org/10.1109/ITAB.2010.5687795

5. Karen Barad. 2003. Posthumanist Performativity: Toward an Understanding of How Matter Comes to Matter. Signs: Journal of Women in Culture and Society 28, 3

6. Ruth Bartlett and Deborah O'Connor. 2007. From personhood to citizenship: Broadening the lens for dementia practice and research. Journal of Aging Studies 21, 2: 107-118. http://doi.org/10.1016/j.jaging.2006.09.002

7. Raewyn Bassett and Janice E. Graham. 2007. Memorabilities: enduring relationships, memories and abilities in dementia. Ageing and Society 27, 4: 533. http://doi.org/10.1017/S0144686X07005971

8. Anne Davis Basting. 2003. Looking back from loss: Views of the self in Alzheimer's disease. Journal of Aging Studies 17, 1: 87-99. http://doi.org/10.1016/S0890-4065(02)00092-0

9. Rachel Batchelor, Ania Bobrowicz, Robin Mackenzie, and Alisoun Milne. 2012. Challenges of ethical and legal responsibilities when technologies' uses and users change: Social networking sites, decision-making capacity and dementia. Ethics and Information Technology 14, 2: 99-108. http://doi.org/10.1007/s10676-012-9286-X

10. Rakel Berenbaum, Yehudit Lange, and Leah Abramowitz. 2011. Augmentative alternative communication for Alzheimer's patients and families' using SAVION. Proceedings of the 4th
International Conference on PErvasive Technologies Related to Assistive Environments (PETRA '11). http://doi.org/10.1145/2141622.2141677

11. Geraldine Boyle. 2013. "She"s usually quicker than the calculator': Financial management and decisionmaking in couples living with dementia. Health and Social Care in the Community 21, 5: 554-562. http://doi.org/10.1111/hsc.12044

12. Dawn Brooker. 2007. Person-Centred Dementia Care: Making Services Better. Jessica Kingsley Publishers.

13. Bernheim A.J. Brush, Kori M. Inkpen, and Tee Kimberly. 2008. SPARCS: exploring sharing suggestions to enhance family connectedness. Proceedings of the 2008 ACM conference on Computer supported cooperative work (CSCW'08): 629-638.

http://doi.org/http://doi.acm.org/10.1145/1460563.1 460661

14. Kathy Charmaz. 2008. Constructionism and the Grounded Theory Method. In Handbook of Constructionist Research, James A. Holstein and Jaber F. Gubrium (eds.). Guilford Press, 397-412.

15. Kathy Charmaz. 2014. Constructing Grounded Theory. Sage Publications, London.

16. Jiska Cohen-Mansfield. 2001. Nonpharmacologic interventions for inappropriate behaviors in dementia: a review, summary, and critique. The American Journal of Geriatric Psychiatry 9, 4: 361381. http://doi.org/10.1176/appi.ajgp.9.4.361

17. Raymundo Cornejo, Robin Brewer, Caroline Edasis, and Anne Marie Piper. 2016. Vulnerability, Sharing, and Privacy: Analyzing Art Therapy for Older Adults with Dementia. Proceedings of the 19th ACM Conference on Computer-Supported Cooperative Work \& Social Computing (CSCW'16), ACM Press, 1572-1583.

18. Raymundo Cornejo, Jesús Favela, and Mónica Tentori. 2010. Ambient Displays for Integrating Older Adults into Social Networking Sites. In Collaboration and Technology, G. Kolfschoten, T. Herrmann and S. Lukosch (eds.). Springer Berlin, Heidelberg, 321-336.

19. David Coyle, James Moore, Per Ola, Kristensson Paul, and C Fletcher Alan. 2012. I did that! Measuring Users' Experience of Agency in their own Actions. Proceedings of the SIGCHI Conference on Human Factors in Computing Systems (CHI '12), 2025-2034.

20. Claire Craig. 2004. Reaching Out with the Arts: Meeting with the Person with Dementia. In 
Dementia and Social Inclusion: Marginalised groups and marginalised areas of dementia research, care and practice, Anthea Innes and Carole Archibald (eds.). Jessica Kingsley Publishers, 184-198.

21. David A. Crocker and Ingrid Robeyns. 2009. Capability and Agency. In Amartya Sen. 60-90.

22. Betsy van Dijk, Pavan Dadlani, Aart van Halteren, and Margit Biemans. 2010. Life changes, connection stays: Photo Sharing and Social Connectedness for People with Special Needs. Proceedings of the 28th Annual European Conference on Cognitive Ergonomics (ECCE '10), August: 135-142. http://doi.org/10.1145/1962300.1962327

23. Ellen Dissanayake. 1999. "Making special": An undescribed human universal and the core of a behavior of art. In Biopoetics. Evolutionary explorations in the arts, B. Cooke and F. Turner (eds.). Lexington: ICUS, 27-46.

24. Paul Dourish. 2001. Where the Action is: The Foundations of Embodied Interaction. MIT Press.

25. Sherry L. Dupuis, Jennifer Gillies, Jennifer Carson, et al. 2011. Moving beyond patient and client approaches: Mobilizing "authentic partnerships" in dementia care, support and services. Dementia 11, 4: 427-452.

http://doi.org/10.1177/1471301211421063

26. Charlotte Emmett, Marie Poole, John Bond, and Julian C Hughes. 2013. Homeward bound or bound for a home? Assessing the capacity of dementia patients to make decisions about hospital discharge: Comparing practice with legal standards. International Journal of Law and Psychiatry 36: 7382. http://doi.org/10.1016/j.ijlp.2012.11.009

27. Aline C. Gubrium, Amy L. Hill, and Sarah Flicker. 2014. A situated practice of ethics for participatory visual and digital methods in public health research and practice: A focus on digital storytelling. American Journal of Public Health 104, 9: 16061614. http://doi.org/10.2105/AJPH.2013.301310

28. Nancy Harding and Colin Palfrey. 1997. The Social Construction of Dementia: Confused Professionals? Jessica Kingsley Publishers.

29. Edwin Hutchins. 1995. Cognition in the Wild. MIT Press.

30. Emily R. Johnson. Patient Art Exhibitions in Health Care Setting. In Art Therapy and Health Care, Cathy A. Malchiodi (ed.). The Guilford Press.

31. Anu Kankainen and Vilma Lehtinen. 2011. Creative personal projects of the elderly as active engagements with interactive media technology.
Proceedings of the 8th ACM conference on Creativity and cognition (C\&C '11): 175-184. http://doi.org/10.1145/2069618.2069648

32. Noriaki Kuwahara, Shinji Abe, Kiyoshi Yasuda, and Kazuhiro Kuwabara. 2006. Networked reminiscence therapy for individuals with dementia by using photo and video sharing. Proceedings of the 8th international ACM SIGACCESS conference on Computers and accessibility (Assets '06), ACM Press, 125. http://doi.org/10.1145/1168987.1169010

33. Amanda Lazar, Raymundo Cornejo, Caroline Edasis, and Anne Marie Piper. 2016. Designing for the Third Hand: Empowering Older Adults with Cognitive Impairments through Creating and Sharing. Proceedings of the 2016 ACM Conference on Designing Interactive Systems (DIS '16), 10471058

34. Hannah Limerick, David Coyle, and James W Moore. 2014. The experience of agency in humancomputer interactions: a review. Frontiers in Human Neuroscience 8: Article 643. http://doi.org/10.3389/fnhum.2014.00643

35. Siân E. Lindley. 2012. Shades of lightweight: Supporting cross-generational communication through home messaging. Universal Access in the Information Society 11, 1: 31-43. http://doi.org/10.1007/s10209-011-0231-2

36. Nancy L. Mace. 1987. Principles of activities for persons with dementia. Physical \& Occupational Therapy in Geriatrics 5, 3: 13-27. http://doi.org/http://dx.doi.org/10.1300/J148v05n03 - 03

37. Robin Mackenzie and John Watts. 2011. Including Emotionality in Tests of Competence: How Does Neurodiversity Affect Measures of Free Will and Agency in Medical Decision Making? AJOB Neuroscience 2, 20 27-36. http://doi.org/10.1080/21507740.2011.580491

38. Sarah MacPherson, Michael Bird, Katrina Anderson, Terri Davis, and Annaliese Blair. 2009. An art gallery access programme for people with dementia: "you do it for the moment". Aging \& Mental health 13, 5: 744-752. http://doi.org/10.1080/13607860902918207

39. Marshall McLuhan. 1964. Understanding Media: The extensions of Man. MIT Press.

40. Kellie Morrissey and John Mccarthy. 2015. Creative and Opportunistic Use of Everyday Music Technologies in a Dementia Care Unit. Proceedings of the 2015 ACM SIGCHI Conference on Creativity and Cognition (C\&C '15), 295-298.

41. Kellie Morrissey, Gavin Wood, David Green, Nadia 
Pantidi, and John Mccarthy. 2016. "I"m a rambler, I'm a gambler, I'm a long way from home': The Place of Props, Music, and Design in Dementia Care. Proceedings of the 2016 ACM Conference on Designing Interactive Systems (DIS '16): 10081020 .

42. Maurice Mulvenna, Stefan Sävenstedt, Franka Meiland, Rose Marie, and David Craig. 2010. Designing \& Evaluating a Cognitive Prosthetic for People with Mild Dementia. Proceedings of the ECCE 2010 Congerence, 11-18.

43. Aisling Ann O'Kane, Helena M Mentis, and Eno Thereska. 2013. Non-Static Nature of Patient Consent: Shifting Privacy Perspectives in Health Information Sharing. Proceedings of the 2013 conference on Computer supported cooperative work (CSCW'13), 553-562.

44. William Odom, Richard Banks, Richard Harper, David Kirk, Siân Lindley, and Abigail Sellen. 2012. Technology Heirlooms? Considerations for Passing Down and Inheriting Digital Materials. Proceedings of the SIGCHI Conference on Human Factors in Computing Systems (CHI '12): 337-346. http://doi.org/10.1145/2207676.2207723

45. Jonathan Parker. 2005. Constructing Dementia and Dementia Care: Daily Practices in a Day Care Setting. Journal of Social Work 5, 3: 261-278. http://doi.org/10.1177/1468017305058935

46. T. Perrin. 1997. The Positive Response Schedule for Severe Dementia. Aging \& mental health 1, 2: 184 191. http://doi.org/10.1080/13607869757290

47. Andrew Pickering. 1995. The Mangle of Practice: Time, Agency, and Science. The University of Chicago Press, Chicago and London.

48. Anne Marie Piper, Raymundo Cornejo, Lisa Hurwitz, and Caitlin Unumb. 2016. Technological Caregiving: Supporting Online Activity for Adults with Cognitive Impairments. Proceedings of the 2016 CHI Conference on Human Factors in Computing Systems (CHI '16): 5311-5323. http://doi.org/10.1145/2858036.2858260

49. Gloria Puurveen, A Phinney, S Cox, and B Purvest. 2015. Ethical issues in the use of video observations with people with advanced dementia and their caregivers in nursing home environments. Visual Methodologies 3, 2: 1-39.

50. Yvonne Rogers, Jeni Paay, Margot Brereton, Kate Vaisutis, Gary Marsden, and Frank Vetere. 2014. Never Too Old: Engaging Retired People Inventing the Future with MaKey MaKey. Proceedings of the SIGCHI Conference on Human Factors in Computing Systems (CHI '14), ACM Press, 3913-
3922.

51. Daniela K Rosner. 2012. The Material Practices of Collaboration. Proceedings of the ACM 2012 conference on Computer Supported Cooperative Work (CSCW'12), 1155-1164.

52. Steven R. Sabat, Lisa Napolitano, and Heather Fath. 2004. Barriers to the construction of a valued social identity: A case study of Alzheimer's disease. American Journal of Alzheimer's Disease and Other Dementias 19, 3: 177-185. http://doi.org/10.1177/153331750401900311

53. Amartya Sen. 1999. Development as Freedom. New York, New York. http://doi.org/10.1215/0961754X9-2-350

54. Ben Shneiderman. 1997. Designing the User Interface: Strategies for Effective Human-Computer Interaction. Addison-Wesley Longman Publishing Co., Inc., Boston, MA.

55. Carol Bowlby Sifton. 2000. Well-Being and Doing: Enabling Occupation with Persons with Dementia. Alzheimer's Care Quarterly 1, 2: 7-28.

56. Emma Snelling, Denise Gregson, and Mike Bender. 2000. Restoring the give and take in a relationship. Journal of Dementia Care 8, 1. http://doi.org/10.1017/CBO9781107415324.004

57. Robert S Stewart, Peter Bartlett, and Rowan H Harwood. 2005. Mental capacity assessments and discharge A way forward. Age and ageing 34: 549 550. http://doi.org/10.1093/ageing/afi185

58. Lucy Suchman. Agencies in Technology Design: Feminist Reconfigurations. Online Proceedings of the 5th European Symposium on Gender \& ICT. http://doi.org/10.1017/CBO9781107415324.004

59. Janelle S. Taylor. 2008. On Recognition, Caring, and Dementia. Medical Anthropology Quarterly 22, 4: 313-335. http://doi.org/10.1111/j.15481387.2008.00036.x

60. Jakob Tholander, Maria Normark, and Chiara Rossitto. 2012. Understanding agency in interaction design materials. Proceedings of the SIGCHI Conference on Human Factors in Computing Systems (CHI'12).

61. Päivi Topo. 2008. Technology Studies to Meet the Needs of People With Dementia and Their Caregivers: A Literature Review. Journal of Applied Gerontology 28, 1: 5-37. http://doi.org/10.1177/0733464808324019

62. P Topo, M Jylhä, and J Laine. 2002. Can the telephone-using abilities of people with dementia be promoted? An evaluation of a simple-to-use telephone. Technology \& Disability 14: 3-13. 
Retrieved from http://search.ebscohost.com/login.aspx?direct=true $\& \mathrm{db}=\operatorname{cin} 20 \& \mathrm{AN}=2002135544 \&$ site $=$ ehost-live

63. John Vines, Rachel Clarke, Peter Wright, John McCarthy, and Patrick Olivier. 2013. Configuring participation: on how we involve people in design. Proceedings of the SIGCHI Conference on Human Factors in Computing Systems (CHI '13), ACM Press, 429-438. http://doi.org/10.1016/S0142694X(98)00026-X

64. Jayne Wallace, Anja Thieme, Gavin Wood, Guy Schofield, and Patrick Olivier. 2012. Enabling self, intimacy and a sense of home in dementia: An Enquiry into Design in a Hospital Setting. Proceedings of the SIGCHI Conference on Human Factors in Computing Systems (CHI '12), ACM Press, 2629-2638. http://doi.org/10.1145/2207676.2208654

65. Jayne Wallace, Peter C. Wright, John McCarthy, David Philip Green, James Thomas, and Patrick Olivier. 2013. A design-led inquiry into personhood in dementia. Proceedings of the SIGCHI Conference on Human Factors in Computing Systems (CHI '13), ACM Press, 2617-2626. http://doi.org/10.1145/2470654.2481363
66. Lin Wan, Claudia Müller, Volker Wulf, and David William Randall. 2014. Addressing the subtleties in dementia care: Pre-study \& Evaluation of a GPS Monitoring System. Proceedings of the SIGCHI Conference on Human Factors in Computing Systems (CHI '14): 3987-3996. http://doi.org/10.1145/2556288.2557307

67. Jenny Waycott, Frank Vetere, Sonja Pedell, et al. 2013. Older adults as digital content producers. Proceedings of the SIGCHI Conference on Human Factors in Computing Systems (CHI '13), 39-48. http://doi.org/10.1145/2470654.2470662

68. Chiara Zaccarelli, Giulio Cirillo, Simone Passuti, Roberta Annicchiarico, and Francesco Barban. 2013. Computer-based cognitive intervention for dementia. Sociable: motivating platform for elderly networking, mental reinforcement and social interaction. Proceedings of the 2013 7th International Conference on Pervasive Computing Technologies for Healthcare (Pervasive Health), Ieee, 430-435. http://doi.org/10.4108/pervasivehealth.2013.252155

69. TopCodes: Tangible Object Placement Codes. Retrieved from http://users.eecs.northwestern.edu/ mhorn/topcodes / 